\title{
Device Complete Loss of Power
}

National Cancer Institute

\section{Source}

National Cancer Institute. Device Complete Loss of Power. NCI Thesaurus. Code C133517.

Problem associated with the lack of power to run a device. 